\title{
Hemorrhage of brain metastasis from non-small cell lung cancer post gefitinib therapy: two case reports and review of the literature
}

\author{
Dan-Fang Yan ${ }^{1}$, Sen-Xiang Yan ${ }^{1 *}$, Jing-Song Yang ${ }^{1}$, Yi-Xiang J Wang ${ }^{2}$, Xiao-Li Sun ${ }^{1}$, Xin-Biao Liao ${ }^{1}$, Jun-Qing Liu ${ }^{1}$
}

\begin{abstract}
Background: Gefitinib is one of the small molecule inhibitors of epidermal growth factor receptor tyrosine kinase (EGFR TKIs). Clinical trials have demonstrated it is effective for treatment of a subset of patients with advanced non-small cell lung cancer (NSCLC). Gefitinib has been generally considered to be a relatively safe agent. Besides a small proportion of fatal interstitial pneumonia, the common adverse drug reactions of gefitinib include diarrhea and skin rash, which are generally mild and reversible. Herein, we report the first two cases of brain metastasis hemorrhage that might be involved with the use of gefitinib.

Case presentation: Two patients with brain metastasis from NSCLC developed brain hemorrhage after gefitinib therapy. The hemorrhage in one case occurred one month after gefitinib combined with whole brain radiation therapy (WBRT), and in the another case hemorrhage developed slowly within brain metastases eight months post gefitinib monotherapy for diffuse pulmonary metastasis from a lung cancer undergone surgical removal previously.

Conclusion: We speculate brain hemorrhage could be one of the adverse drug reactions of gefitinib treatment for NSCLC and suggest clinicians be aware of this possible rare entity. More data are needed to confirm our findings, especially when gefitinib is used in the settings of brain metastases from NSCLC or other origins.
\end{abstract}

\section{Background}

Gefitinib is one of the inhibitors of epidermal growth factor receptor tyrosine kinase (EGFR TKIs), designed to offer targeted therapies for a variety of solid tumors including the lung cancer [1]. Clinical trials have demonstrated that gefitinib is effective or non-inferior to chemotherapy in the treatment of a subset of patients with advanced non-small cell lung cancer (NSCLC) [2-4]. Gefitinib has also been regarded as a relatively safe agent, with the most common adverse drug reactions being diarrhea and skin rash, which are generally mild in nature and reversible $[5,6]$. Here we describe two cases of brain metastasis from NSCLC who developed brain hemorrhage post gefitinib therapy. To our knowledge, these are the first reported cases of brain hemorrhage that might be involved in the use of gefitinib. Recently, a few hemorrhagic events in other parts of the body have also been reported after gefitinib

\footnotetext{
* Correspondence: yansenxiang@zju.edu.cn

'Department of Radiation Oncology, the First Affiliated Hospital, College of Medicine, Zhejiang University, Hangzhou, Zhejiang 310003, PR China
}

administration [7-9]. Thus, we speculate brain hemorrhage could be one possible adverse drug reaction of gefitinib treatment for NSCLC.

\section{Case presentation}

\section{Case one}

A 52-year-old male, who was an ex-smoker with a smoking history of ten years, was found a solitary pulmonary nodule (SPN) in the upper lobe of right lung by CT scans 6 years ago. He refused surgery or any invasive procedures to the nodule. Chest CT scan was performed every six months for follow-up. In May 2009 CT demonstrated the SPN increased in size with multiple lung and ribs metastasis (Fig. 1A). Brain MRI showed multiple metastatic lesions with the largest one in the left occipital lobe (Fig. 2A). CT-guided percutaneous needle biopsy of the pulmonary lesion proved adenocarcinoma. After refusing chemotherapy with toxic agents, gefitinib (AstraZeneca, UK) was given at a daily dose of $250 \mathrm{mg}$ as the first-line treatment for NSCLC combined concurrently with whole brain irradiation (WBRT) for 

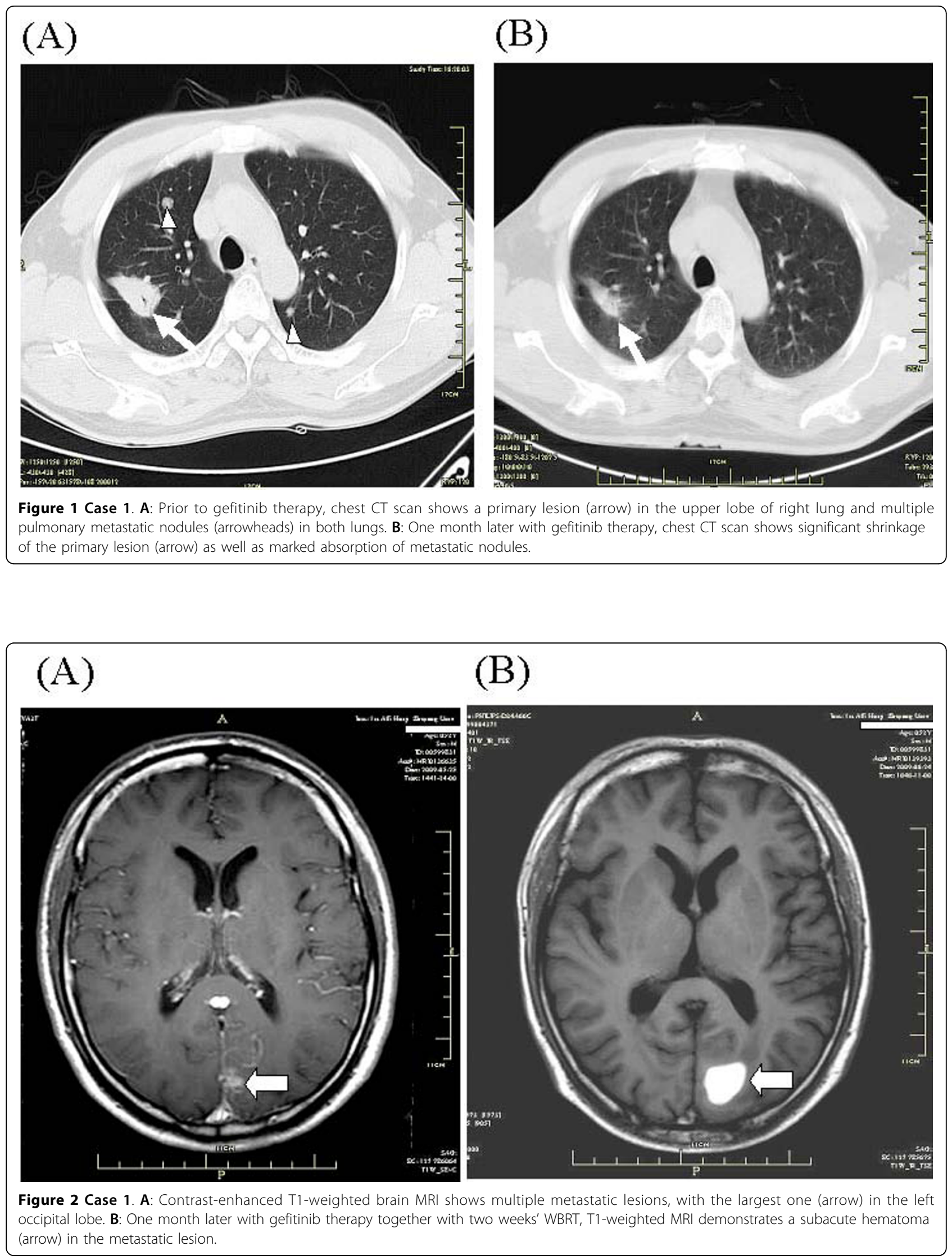
the metastatic brain tumors. WBRT was performed to a total dose of 30 Gy with a fraction size of 3 Gy over 2 weeks. During the course of treatment, mild skin rash and nausea and vomiting developed but were well tolerated. One month later, chest CT showed significant shrinkage of the primary lesion and marked absorption of pulmonary metastases (Fig. 1B). Meanwhile, the patient began to feel recurrent headache and nausea, and brain MRI demonstrated a left occipital lobe mass that was consistent with a subacute hematoma (Fig. 2B). The platelet counts and prothrombin time and activated partial thromboplastin time were within normal ranges. The patient had no history of diabetes or hypertension or coagulation disorders. During hospitalization the patient had no history of trauma. Except for mild to moderate headache and nausea, the patient complained of no other discomfort such as impaired orientation to person and place, hemidysesthesia or hemiopia. The patient was discharged from hospital after one week's supportive treatment with mannitol and methylprednisolone.

\section{Case two}

A 75-year-old male, an ex-smoker, was diagnosed with right lower lobe lung cancer in July 2007, and underwent operation after routine staging procedures. The pathology was adenocarcinoma with positive margins and ipsilateral hilar and mediastinal lymph node metastasis (Stage pT3N2M0). Postoperative adjuvant chemotherapy and thoracic radiotherapy (59 Gy/32 fractions) were administered. The patient was well tolerant to these therapies and without evidence of illness until July 2008, when CT scans demonstrated diffuse pulmonary metastatic dissemination (Fig. 3A) and a metastasis in right hepatic lobe. The patient was given gefitinib at a daily dose of $250 \mathrm{mg}$. CT scans about 2 months later showed near-CR (Complete Response) of the pulmonary lesions (Fig. 3B). After five months' medication of gefitinib, the patient developed severe bilateral paronychia. This patient had an operation of nail arrachement in November 2008. In March 2009, the patient developed right limb numbness and unstable walking. Brain MRI demonstrated a metastatic tumor in the left thalamus with intratumoral hemorrhage (Fig. 4). The platelet counting of the patient was $143,000 / \mathrm{mm}^{3}$ and there were no other underlying disorders that might be related to the brain hemorrhage. WBRT was recommended but the patient preferred watchful waiting. On 5 th June 2009, more metastatic lesions with evidence of bleeding were found on brain MRI and subsequently WBRT (30 Gy/15 fractions) was administered to the patient. The patient is now still alive with mild right hemiparesis.

\section{Discussion}

Epidermal growth factor receptor (EGFR) is a member of the HER tyrosine kinase growth factor receptor family that signals cellular differentiation, proliferation,

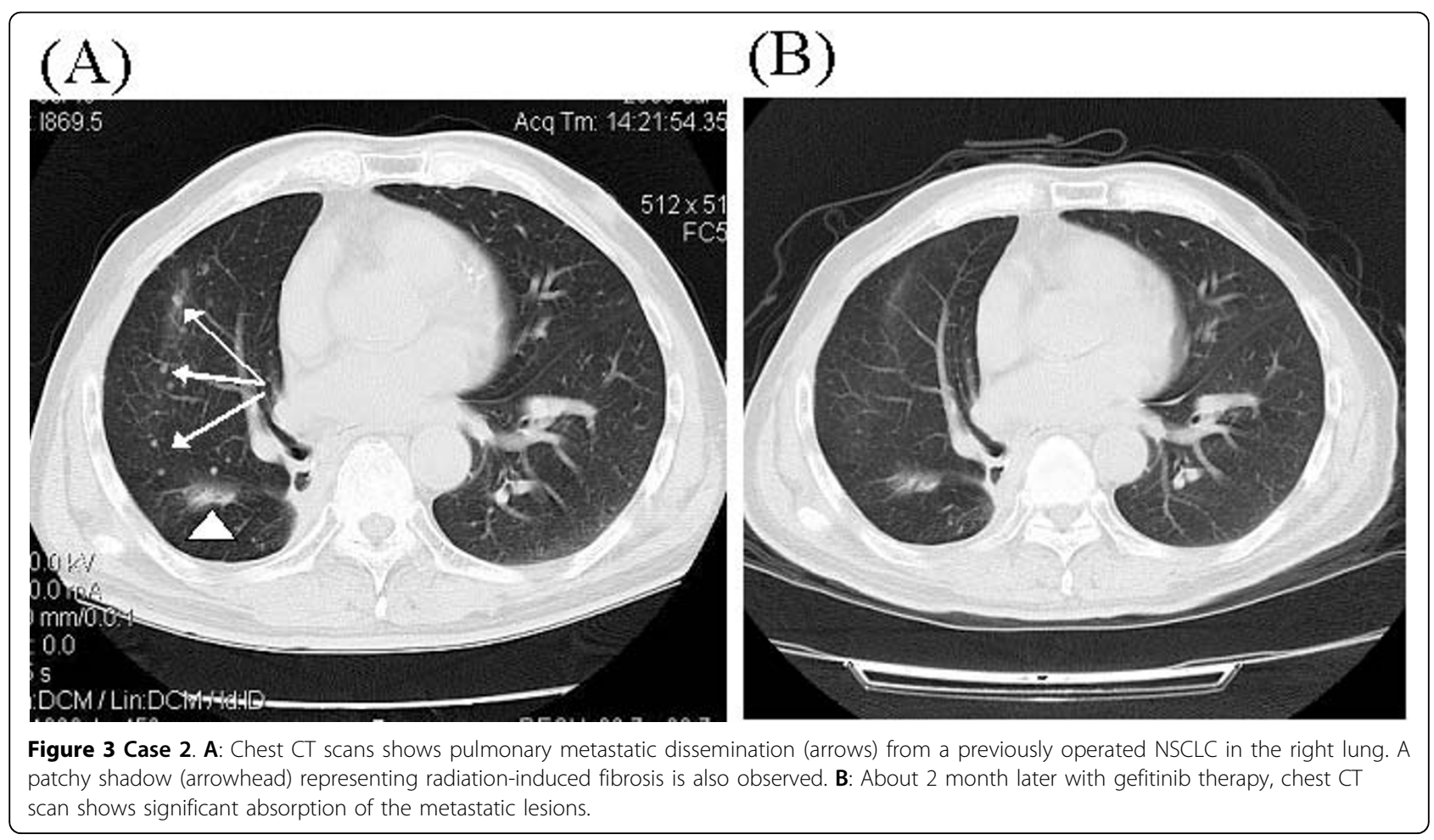




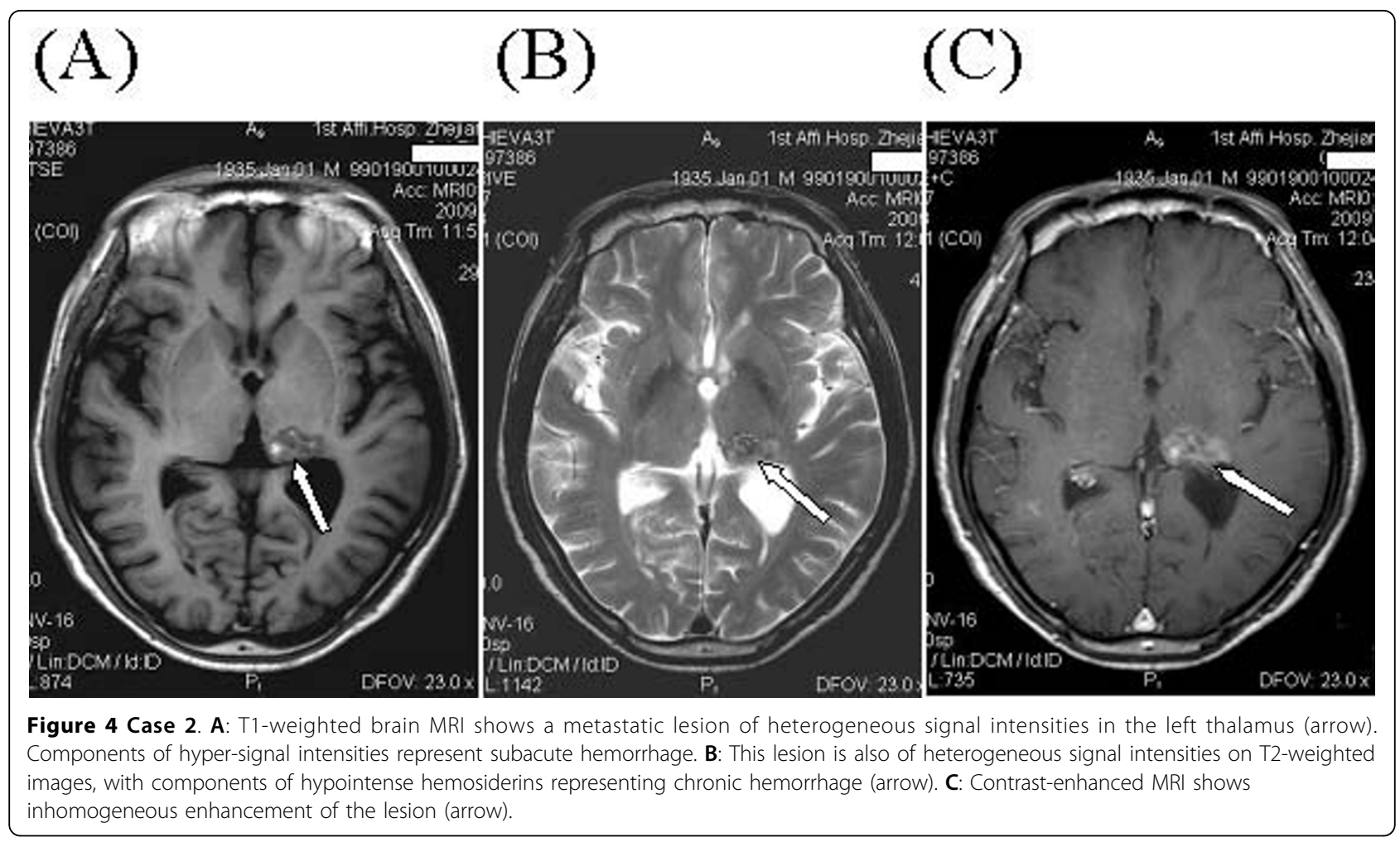

invasion, metastasis, and survival. It is expressed in a variety of human cancers including NSCLC (40\%-80\%), colorectal (25\%-77\%), pancreatic (30\%-50\%), breast (15\%-30\%), ovarian (35\%-70\%), prostate $(40 \%)$ and gastric (33\%) cancers [1]. Among the above-mentioned cancers, NSCLC was one of the most frequently studied objects of EGFR-targeted therapy, as evidenced by such clinical trials as INTEREST, ISEL (for gefitinib), and BR21 and SATURN (for erlotinib, another EGFR-TKI) [2,4,10,11].

Gefitinib (ZD1839, Iressa), a selective inhibitor of EGFR tyrosine kinase (EGFR-TKI) which is competitive with the combination of EGFR tyrosine kinase, acts through blocking the signal transduction pathway of epithelial growth factor and thereby inhibiting the proliferation and metastasis, and, promoting the apoptosis of tumor cells [1]. The orally administered gefitinib has achieved a great effect since its approval by FDA in 2003, for it has less toxicity compared with traditional cytotoxic chemotherapy. In addition to an extremely small number of fatal interstitial pneumonia reported [12], the common adverse drug reactions of gefitinib are diarrhea, skin rash, dry skin, nausea and vomiting. On most occasions these reactions are mild and reversible. Other less common adverse effects include pruritus, anorexia, asthenia, and weight loss [13]. For the above reasons, gefitinib has been used as the second or third line therapy for advanced and metastatic NSCLC, or even evaluated as the first line therapy (IPASS trial) for a subset of patients with NSCLC [14]. Our first case was administered gefitinib without prior cytotoxic therapies.

Targeted therapies also aim at other signal transduction pathways like vascular endothelium growth factor (VEGF). It was reported that anti-angiogenic therapy (AAT) had led to serious hemorrhagic events in NSCLC, particularly in those of squamous cell origin [15]. An early phase I trial of bevacizumab, an antiVEGF monoclonal antibody, also detected a case of intracranial hemorrhage from a choriocarcinoma brain metastasis. However, a recent phase II trial, AVF3752g, showed safety of bevacizumab in patients with NSCLC and previously treated brain metastases [16]. On the other hand, anti-EGFR therapy has seldom been warned against increased risks of bleeding, except a few case reports of anecdotal experience.

There has been a case report in which severe alveolar hemorrhage occurred after four weeks' gefitinib therapy in a 56-year-old man of NSCLC in Japan [9]. Recently, another two reports on bilateral subdural hemorrhage (SDH) after oral gefitinib administration have been published $[7,8]$. In one, a 75-year-old woman was diagnosed as stage IV NSCLC and was introduced to take gefitinib at a daily dose of $250 \mathrm{mg}$. About 7 months later, the patient gradually developed headache and weakness, and CT demonstrated bilateral SDH another 2 months later. Although there was no obvious evidence of CNS 
metastasis, the authors still thought that bilateral SDH might had resulted from obstruction of dural vessels by latent dural metastasis and was also suggested as a possible adverse event of gefitinib therapy. Notably, the above-described two cases developed hemorrhagic events without CNS metastasis. Huang et al [8] reported another case where a 57-year-old male developed bilateral SDH after WBRT combined with EGFR-TKIs for NSCLC with brain metastases. Gefitinib was replaced with erlotinib on the 5th day after WBRT. During a follow-up period with erlotinib alone after completing WBRT, the patient developed bilateral SDH. The authors did not make a clear explanation for the complication. Apart from the above reports of hemorrhagic events that might be related to gefitinib in NSCLC, there was also a recent phase III study showing gefitinib dose-dependently increased tumor hemorrhage-type events in recurrent squamous cell carcinoma of the head and neck [17].

In the current report, two patients developed brain metastasis hemorrhage after taking gefitinib. Though in our first case brain tumor hemorrhage developed one month after a combination of gefitinib and WBRT, it is still possible that gefitinib played a role. There were no comorbiditis such as thrombocytopenia, coagulation abnormalities or other underlying cerebrovascular diseases or head trauma, and our own experience and reports from other authors suggested that WBRT alone was unlikely to be the cause of tumoral hemorrhage of brain metastases, but rather could decrease the hemorrhagic events through blunting angiogenesis and normalizing tumor vasculature $[18,19]$. As considerable studies have demonstrated gefitinib to be a radiation sensitizer in the treatment of a variety of tumors including NSCLC, head and neck, breast, and colorectal cancers $[20,21]$, we think EGFR-targeted therapy may have strengthened the role of radiation-induced vascular occlusion and subsequent post-ischemic hemorrhage. Furthermore, gefitinib in combination with WBRT might lead to rapid shrinkage of brain metastasis and avascular necrosis, and induce reconstruction of microvasculature and vascular abnormality, subsequently leading to tumoral bleeding. This is especially true for those with high expression or mutations of EGFR. Unfortunately, our two cases have not been performed that kind of test, though patients now in our institute are strongly encouraged to take such test before taking gefitinib or other TKIs.

In the second case, hemorrhagic brain metastasis was found 8 months after gefitinib monotherapy. Before that, the patients also experienced severe paronychia and underwent a nail arrachement three months after gefitinib administration. MRI showed evidence of both subacute (hyperintensities on T1-weighted image) and chronic (hypointensities on T2-weighted image) components of bleeding, with no obvious perilesional edema, which might accounted for the mild symptoms and signs of the patients. For the above reasons, the patient was not immediately administered WBRT until some new hemorrhagic metastases were detected in other parts of the brain. As reported in the literature, the incidence of spontaneous intracranial hemorrhage from NSCLC with brain metastasis seemed to be very low (about 1.2\%), though higher than those without CNS metastasis [22,23]. Furthermore, recent studies on EGFR inhibition with gefitinib also showed its influence on angiogenesis [24]. Hence, though whether the brain metastasis hemorrhages were just coincidence or as a result of gefitinib therapy remain to be further confirmed, it seems possible that gefitinib might be involved in the brain hemorrhage in our two cases. Interestingly, there is a study on treatment of brain metastasis from NSCLC with WBRT and gefitinib which showed acute side effects were generally well tolerated, and no hemorrhagic events were mentioned [6], our experience suggest that caution should be taken when gefitinib is used in combination with WBRT.

\section{Conclusion}

In summary, from our cases and others reported in the literature, we speculate that brain metastasis hemorrhage could be a possible adverse drug reaction of gefitinib for treatment of NSCLC. With increasing use of gefitinib, especially in those patients with EGFR overexpression or mutations, it is reasonable to suggest that clinicians be highly cautious about this possible complication.

\section{Consent}

Written informed consent was obtained from the patient for publication of this case report and any accompanying images. A copy of the written consent is available for review by the Editor-in-Chief of this journal.

\section{Author details \\ 'Department of Radiation Oncology, the First Affiliated Hospital, College of Medicine, Zhejiang University, Hangzhou, Zhejiang 310003, PR China. 2Departments of Diagnostic Radiology and Organ Imaging, the Chinese University of Hong Kong, Prince of Wales Hospital, Shatin, Hong Kong, PR China.}

\section{Authors' contributions}

DFY and YXJW analyzed the data and wrote the manuscript. JSY, XLS, XBL. and JQL made substantial contributions in data acquisition and data interpretation. SXY participated in study design and coordination. All authors read and approved the final manuscript.

\section{Competing interests}

The authors declare that they have no competing interests. 
Received: 28 August 2009 Accepted: 21 February 2010

Published: 21 February 2010

\section{References}

1. Raymond E, Faivre S, Armand JP: Epidermal growth factor receptor tyrosine kinase as a target for anticancer therapy. Drugs 2000, 60:15-23.

2. Thatcher N, Chang A, Parikh P, Rodrigues Pereira J, Ciuleanu T, von Pawel J, Thongprasert S, Tan EH, Pemberton K, Archer V, Carroll K: Gefitinib plus best supportive care in previously treated patients with refractory advanced non-small-cell lung cancer: results from a randomised, placebo-controlled, multicentre study (Iressa Survival Evaluation in Lung Cancer). Lancet 2005, 366:1527-37.

3. Niho S, Ichinose $Y$, Tamura T, Yamamoto N, Tsuboi M, Nakagawa K, Shinkai T, Jiang H, Nishiwaki Y, Fukuoka M: Results of a randomized phase iii study to compare the overall survival of gefitinib (IRESSA) versus docetaxel in Japanese patients with non-small-cell lung cancer who failed one or two chemotherapy regimens. Proc Am Soc Clin Oncol 2007, 25(18S), [abstr LBA7509].

4. Kim ES, Hirsh V, Mok T, Socinski MA, Gervais R, Wu YL, Li LY, Watkins $C L$, Sellers MV, Lowe ES, Sun Y, Liao ML, Osterlind K, Reck M, Armour AA, Shepherd FA, Lippman SM, Douillard JY: Gefitinib versus docetaxel in previously treated non-small-cell lung cancer (INTEREST): a randomised phase III trial. Lancet 2008, 372:1809-18

5. Park J, Park BB, Kim JY, Lee SH, Lee SI, Kim HY, Kim JH, Park SH, Lee KE, Park JO, Kim K, Jung CW, Park YS, Im YH, Kang WK, Lee MH, Park K: Gefitinib (ZD1839) monotherapy as a salvage regimen for previously treated advanced non-small cell lung cancer. Clin Cancer Res 2004, 10:4383-8.

6. Ma S, Xu Y, Deng $Q, Y u X$ : Treatment of brain metastasis from non-small cell lung cancer with whole brain radiotherapy and Gefitinib in a Chinese population. Lung Cancer 2009, 65:198-203.

7. Kim JH, Kim HS, Choi JS, Lee KM, Shin YC, Ahn BM, Choi DR, Kwon JH, Park S, Kim HY, Jung JY, Kim HJ, Song HH, Zang DY: Bilateral subdural hemorrhage as a possible adverse event of gefitinib in a patient with non-small cell lung cancer. Lung Cancer 2009, 64:121-23.

8. Huang YJ, Liu SF, Wang CJ, Huang MY: Exacerbated radio dermatitis and bilateral subdural hemorrhage after whole brain irradiation combined with epidermal growth factor receptor tyrosine kinase inhibitors for brain metastases in lung cancer. Lung Cancer 2008, 59:407-10.

9. leki R, Saitoh E, Hashimoto E, Ohta T, Yuasa K, Iquchi M, Okamura T, Shibuya M, Moriyama S, Goto H: Alveolar hemorrhage as a possible adverse drug reaction by gefitinib (ZD Iressa). Gan To Kagaku Ryoho 1839, 30:977-80

10. Shepherd FA, Rodrigues Pereira J, Ciuleanu T, Tan EH, Hirsh V, Thongprasert S, Campos D, Maoleekoonpiroj S, Smylie M, Martins R, van Kooten M, Dediu M, Findlay B, Tu D, Johnston D, Bezjak A, Clark G, Santabárbara P, Seymour L, National Cancer Institute of Canada Clinical Trials Group: Erlotinib in previously treated non-small-cell lung cancer. New Engl J Med 2005, 353:123-32.

11. Cappuzzo F, Ciuleanu T, Stelmakh L, Cicenas S, Szczesna A, Juhasz E, Gonzalez EE, Molinier O, Klingelschmitt G, Giaccone G: SATURN: a doubleblind, randomized, phase III study of maintenance erlotinib versus placebo following nonprogression with first-line platinum-based chemotherapy in patients with advanced NSCLC. Program and abstracts of the 2009 Annual Meeting of the American Society of Clinical Oncology; Orlando, Florida. Abstract 80012009.

12. Inoue A, Saijo Y, Maemondo M: Severe acute interstitial pneumonia and gefitinib. Lancet 2003, 361:137-9.

13. Cohen MH, Williams GA, Sridhara R, Chen G, Pazdur R: FDA drug approval summary: gefitinib (ZD1839) (Iressa) tablets. Oncologist 2003, 8:303-6.

14. Mok TS, Wu YL, Thongprasert S, Yang CH, Chu DT, Saijo N, Sunpaweravong $P$, Han B, Margono B, Ichinose $Y$, Nishiwaki $Y$, Ohe $Y$, Yang JJ, Chewaskulyong B, Jiang H, Duffield EL, Watkins CL, Armour AA, Fukuoka M: Gefitinib or carboplatin-paclitaxel in pulmonary adenocarcinoma. N Engl J Med 2009, 361(10):947-57.

15. Johnson DH, Fehrenbacher L, Novotny WF, Herbst RS, Nemunaitis JJ, Jablons DM, Langer CJ, Kabbinnavar F: Randomized phase II trial comparing bevacizumab plus carboplatin and paclitaxel with carboplatin and paclitaxel alone in previously untreated locally advanced or metastatic non small cell lung cancer. J Clin Oncol 2004, 22:2184-91.
16. Socinski MA, Langer CJ, Huang JE, Kolb MM, Compton P, Wang L, Akerley W: Safety of Bevacizumab in Patients With Non-Small-Cell Lung Cancer and Brain Metastases. J Clin Oncol 2009, 27:5255-61.

17. Stewart JS, Cohen EE, Licitra L, Van Herpen CM, Khorprasert C, Soulieres D, Garin AM, Hirsch FR, Varella-Garcia M, Ghiorghiu S, Hargreaves L, Armour A, Speake G, Swaisland A, Vokes EE: Phase III Study of Gefitinib 250 Compared With Intravenous Methotrexate for Recurrent Squamous Cell Carcinoma of the Head and Neck. J Clin Oncol 2009, 27:1864-71.

18. Raben $D$, Helfrich B: Angiogenesis inhibitors: a rational strategy for radiosensitization in the treatment of non-small-cell lung cancer? Clin Lung Cancer 2004, 6:48-57.

19. Luo X, Andres ML, Timiryasova TM, Fodor I, Slater JM, Gridley DS: Radiation enhanced endostatin gene expression and effects of combination treatment. Technol Cancer Res Treat 2005, 4:193-202.

20. Ochs JS: Rationale and clinical basis for combining gefitinib (IRESSA, ZD1839) with radiation therapy for solid tumors. Int I Radiat Oncol Biol Phys 2004, 58:941-9.

21. Bianco C, Tortora G, Bianco R, Caputo R, Veneziani BM, Caputo R, Veneziani BM, Caputo R, Damiano V, Troiani T, Fontanini G, Raben D, Pepe S, Bianco AR, Ciardiello F: Enhancement of antitumor activity of ionizing radiation by combined treatment with the selective epidermal growth factor-tyrosine kinase inhibitor ZD1839 ('Iressa'). Clin Cancer Res 2002, 8:3250-8

22. Maiuri F, D'Andrea F, Gallicchio B, Carandente M: Intracranial hemorrhages in metastatic brain tumors. J Neurosurg Sci 1985, 29:37-41.

23. Srivastava G, Rana V, Wallace S, Taylor S, Debnam M, Feng L, Suki D, Karp D, Stewart D, Oh Y: Risk of intracranial hemorrhage and cerebrovascular accidents in non-small cell lung cancer brain metastasis patients. J Thorac Oncol 2009, 4:333-37.

24. Guillamo JS, de Bouard S, Valable S, Marteau L, Leuraud P, Marie Y, Poupon MF, Parienti JJ, Raymond E, Peschanski M: Molecular mechanisms underlying effects of epidermal growth factor receptor inhibition on invasion, proliferation, and angiogenesis in experimental glioma. Clin Cancer Res 2009, 15:3697-3704.

Pre-publication history

The pre-publication history for this paper can be accessed here: http://www.biomedcentral.com/1471-2407/10/49/prepub

doi:10.1186/1471-2407-10-49

Cite this article as: Yan et al:: Hemorrhage of brain metastasis from non-small cell lung cancer post gefitinib therapy: two case reports and review of the literature. BMC Cancer 2010 10:49.

\section{Submit your next manuscript to BioMed Central and take full advantage of:}

- Convenient online submission

- Thorough peer review

- No space constraints or color figure charges

- Immediate publication on acceptance

- Inclusion in PubMed, CAS, Scopus and Google Scholar

- Research which is freely available for redistribution 